\title{
O conceito de arquivo e suas múltiplas facetas no cenário brasileiro:
}

\section{as dimensões de um quebra-cabeça}

\author{
Welder Antônio Silva \\ weldsilva@gmail.com \\ Victor Schreiber Cromack \\ crouver@hotmail.com \\ Universidade Federal de Minas Gerais (UFMG) \\ Assembleia Legislativa do Estado de Minas Gerais
}

Resumo: Diante das recentes reflexões epistemológicas na Arquivologia, em virtude dos impactos trazidos pelas TICs, e os questionamentos sobre a identidade e o trabalho do arquivista, acredita-se que tais fenômenos não significam rupturas / descontinuidades, mas que isso precisa ser repensado constantemente, com o objetivo de reconhecer as suas questões fundamentais, os desvios apresentados, as respostas encontradas e as dimensões que se apresentam nos novos cenários. Desta forma, considera-se essencial que os conceitos que fundamentam e orientam a Arquivologia devem ser revisitados. Portanto, a pesquisa que aqui se apresenta teve como objetivo revisitar o conceito de arquivos e suas facetas na literatura brasileira, visualizar como estes foram / são tratados em nível nacional e traçar uma relação com sua concepção no cenário internacional, com base em considerações de MartínPozuelo Campillos (1996), Fuster Ruiz (1999) e Vivas Moreno (2004). Decidiu-se analisar as publicações científicas especializadas, dado que representam a construção de uma identidade científica da área. Como resultado foi possível perceber que a conceituação/caracterização do termo, pelos autores brasileiros, envolve múltiplas facetas que se movimentam e se articulam, tendo em vista as diversas dimensões conjunturais e contextuais e as diferenças de ênfase que se pretende anunciar.

Palavras-chave: Arquivologia; Arquivo; Terminologia arquivística; Epistemologia arquivística

\begin{abstract}
Front of recent epistemological reflections on Archival Science because of the impacts brought by ICTs and the questions about identity and work of the archivist, it is believed that this phenomenon does not mean rupture/discontinuities, but that this needs to be rethought constantly, with the objective of recognize their fundamental questions, the deviations presented, the answers found and the dimensions that present themselves in the new scenarios. In this way it is considered essential that the concepts that underlie and guide Archival Science be revisited. Therefore, this article aims to revisit the concept of archives and its facets in Brazilian literature see how these were/are treated in national and draw a relationship with his conception in the international scenario, based on considerations of Campillos (1996) Ruiz (1999) and Moreno (2004). It was decided to analyze specialized scientific journals, given that they represent the construction of a scientific identity of the area.
\end{abstract}

Keywords: Archival Science; Archives; Archival terminology; Archival epistemology. 
"A vulgarização indiscriminada do termo [arquivo], principalmente por parte de alguns profissionais, pode ser fruto de uma carência teórica ou uma indisposição, muitas vezes compreensível, de alimentar discussões infrutíferas com aqueles que permanecem na ignorância." (SILVA, 2005, p. 55)

\section{INTRODUÇÃO}

Atualmente, tendo em vista as novas configurações trazidas pela dinâmica do fenômeno informacional, as dimensões e questões trazidas pelas tecnologias da informação e comunicação (TICS) e, ainda, pelos novos questionamentos a respeito da identidade e do trabalho do arquivista, tem-se vivenciado uma ampliação de discussões e reflexões epistemológicas na Arquivologia. Ao analisar a área na atualidade, Thomassem (1999), por exemplo, faz um paralelo entre o seu "paradigma clássico" e um possível novo paradigma, considerando, entre outros fatores, o seu objeto (Quadro 1 ). No que tange ao paradigma clássico da Arquivologia, Thomassem (1999) identifica como seu objeto o arquivo ou fundo arquivístico, custodiado por uma instituição arquivística, e as suas principais entidades são os documentos de arquivo enquanto "artefatos" físicos, os quais são considerados orgânicos por natureza. Em relação ao seu possível novo paradigma, este autor explica que as novas tecnologias da informação e da comunicação foram responsáveis por trazer mudanças significativas para o campo da Arquivologia, entre elas, essa ruptura paradigmática ${ }^{1}$, na qual a Arquivologia tem como objeto a informação arquivística ou informação orgânica registrada ${ }^{2}$. Thomassem (1999) explica, ainda, que este objeto é duplo e refere-se à informação arquivística em si (conteúdo semântico) e ao seu contexto de criação (conteúdo diplomático do documento, que revela o conjunto ao qual pertence, a sua forma e estrutura e a entidade física ou jurídica que o criou). Diante do exposto, suas entidades fundamentais, neste caso, também duplas, deslocam-se dos arquivos para a lógica do documento individual e para as suas relações com os processos ou transações administrativas.

\footnotetext{
${ }^{1}$ É importante aqui, destacar que, apesar de reconhecer que estas rupturas paradigmáticas tenham sido provocadas em virtude da chamada Revolução Digital, Thomassem (1999) esclarece que o novo paradigma da Arquivologia não representa simplesmente a passagem dos documentos em papel para os documentos eletrônicos e, sim, citando Cook (1997), uma mudança da Arquivologia clássica ou moderna para uma Arquivologia póscustodial ou pós-moderna.

${ }^{2}$ Termo utilizado pelos arquivistas canadenses Rousseau e Couture (1998).
} 
Quadro 1 - As mudanças paradigmáticas da Arquivologia

\begin{tabular}{l|l|l|l}
\hline \multicolumn{4}{|c}{ PARADIGMATIC CHANGES IN ARCHIVITICS } \\
\hline Period & 19th century & 20th century & 21 century \\
\hline Charac-teristic & pre-paradim stage & classic or modern & post-custodial or post modern \\
\hline Object & $\begin{array}{l}\text { (1) archives of community } \\
\text { (2) diplomas and } \\
\text { registrations }\end{array}$ & $\begin{array}{l}\text { archives of an organization or } \\
\text { an official }\end{array}$ & process bound information \\
unity & $\begin{array}{l}\text { (1) physical item } \\
\text { (2) single diploma and } \\
\text { registration }\end{array}$ & physical item & record \\
\hline Objetive & $\begin{array}{l}\text { (1) Physical and } \\
\text { administrative control } \\
\text { (2) publication }\end{array}$ & $\begin{array}{l}\text { control and accessibility } \\
\text { (physical, administrative and } \\
\text { intellectual control) }\end{array}$ & high quality of information \\
\hline Method & $\begin{array}{l}\text { (1) respect des fonds } \\
\text { (2) diplomatic methods }\end{array}$ & principle of provenance & $\begin{array}{l}\text { principle of provenance } \\
\text { used as a quality instrument }\end{array}$ \\
\hline Techniques & $\begin{array}{l}\text { (1) artificial classification } \\
\text { (2) diplomatic techniques }\end{array}$ & $\begin{array}{l}\text { formal description techniques } \\
\text { natural classification }\end{array}$ & $\begin{array}{l}\text { techniques: descriptive } \\
\text { standards }\end{array}$ \\
\hline
\end{tabular}

Fonte: THOMASSE (1999, p. 8).

Todavia, é importante destacar que, segundo Thomassem (1999), estes fatos não representam uma vitória do novo paradigma sobre o velho paradigma e, portanto, deve-se compreender que um novo paradigma pode representar uma nova orientação e, até mesmo, uma extensão dos domínios do antigo paradigma. Para o autor em questão, o antigo paradigma não deve ser completamente colocado de lado, mas deve ser integrado ao novo domínio definido. De acordo com Thomassem (1999), olhando-se para o objeto da Arquivologia, pode-se perceber que, se o novo paradigma tem como foco os documentos em suas dimensões lógica e dinâmica, esta visão ampla também permite um foco nos documentos físicos e estáticos, de modo que, dentro deste novo domínio, os métodos e técnicas do paradigma clássico ainda são válidos. Além disso, de acordo com o mesmo autor, olhando-se para a metodologia de arquivamento, por exemplo, o princípio da proveniência e da ordem original ainda são utilizados para a formação dos fundos arquivísticos (arquivos) em sua ordem original.

Após ter examinado as ideias arquivísticas do século XX, Cook (1997) também afirma que a Arquivologia está desenvolvendo gradualmente uma estrutura conceitual ou teórica nova, entretanto, dentre os vários pontos que destaca, ressalta, por exemplo, que os arquivos ou fonds d'archives não serão mais concebidos, enquanto estiverem refletindo alguma ordem 
física e estática, fundamentada nas regras de sua acumulação, mas espelhando as múltiplas dinâmicas de criação e autoria dos documentos, focalizadas em torno da função e da atividade do produtor e capturando, de maneira mais exata, a contextualidade dos documentos.

Vale ressaltar que, de acordo com Cook (1997), "a teoria arquivística não deve ser considerada enquanto um jogo de leis científicas imutáveis, estabelecidas desinteressadamente." O autor explica que os principais pensadores arquivísticos do século $X X$, reinventaram o conceito dos arquivos, algumas vezes, de forma inconsciente, e, em outras, de forma consciente, porém, de acordo com os discursos dominantes espaciais e temporais, perpassando por diversas fases sociais. Diante desse pressuposto, Cook (1997) declara que "se reconhecida, esta natureza mutante da teoria arquivística sobre o tempo, esta representará a sua força profissional, não sua fraqueza". Diante desse argumento, o mesmo autor defende que

\begin{abstract}
A história da teoria arquivística não é uma evolução linear, com escolas exclusivas de pensadores [...] [e sim] uma colagem rica de camadas de sobreposição, de ideias contraditórias que existem simultaneamente ou mesmo misturando-se, de pensadores que exibem diferenças de ênfase mais do que de ideias fundamentais, de pensadores individuais que mudam suas ideias à luz das novas circunstâncias, das ideias velhas que aparecem à guisa de novas e em lugares novos. O pêndulo de balanços do pensamento para frente e para trás [...] (COOK, 1997, tradução nossa).
\end{abstract}

Diante destas reflexões acima apresentadas, entende-se que este fenômeno de mudanças epistemológicas e pragmáticas no campo arquivístico não significa, necessariamente, rupturas e descontinuidades, de modo que a Arquivologia não precisa ser refundada. Acredita-se que a Arquivologia precisa ser repensada constantemente, com o objetivo de buscar sempre reconhecer as suas questões fundamentais, os desvios apresentados, as respostas encontradas e as dimensões que se apresentam diante de novos cenários. Sendo assim, seguindo esta linha de pensamento, considera-se essencial que os arquivistas revisitem os conceitos que norteiam e fundamentam a epistemologia e a pragmática arquivística, em especial os conceitos de arquivo, haja vista que, de acordo com Thomassem (2006, p. 5), "o conceito central da Arquivologia é o conceito de arquivo", conceito este que precisa ser definido e compreendido, de forma precisa e criteriosa, pelos arquivistas.

Arquivistas precisam ter um entendimento claro do que significam as expressões arquivos e sistemas de arquivos, e eles precisam saber que funções os arquivos têm, de que entidades fundamentais são compostos e de que modo estas entidades fundamentais se relacionam umas com as outras, e como a qualidade dos arquivos pode ser avaliada e assegurada. Arquivistas precisam deste conhecimento para estarem aptos a implantar 
sistemas de arquivo, analisar estes sistemas e trocar informações sobre eles. (THOMASSEM, 2006, p. 5 ).

Motivado por estes argumentos, o presente artigo tem como foco revisitar os conceitos de arquivo na literatura arquivística brasileira, com o objetivo de visualizar como eles foram abordados através do tempo, no cenário nacional. Para tanto, optou-se por analisar a produção de conhecimento na área arquivística brasileira em periódicos científicos especializados, sendo selecionados dois periódicos editados por Associações de profissionais da área, a saber: Arquivo \& Administração (publicação editada pela Associação dos Arquivistas Brasileiros desde 1972) e Cenário Arquivístico (publicação editada pela Associação Brasiliense de Arquivologia, entre 2002 e 2004).

\section{BREVES CONSIDERAÇÕES SOBRE A DEFINIÇÃO DOS CONCEITOS DE ARQUIVO}

Ao fazer suas considerações sobre o Manual dos Holandeses ${ }^{3}$, Fonseca (2004, p. 83, grifo da autora) ressalta que, nesta publicação, na realidade, todas as 100 normas apresentadas "são decorrentes da primeira, na qual os autores se dedicam a definir o que é um arquivo", e inclusive, "em suas próprias palavras, afirmam 'esta definição de arquivo, que colocamos aqui como base sobre a qual se erguerá todo o resto... '." Ou seja, na concepção de S. Muller, J. A. Feith e R. Fruin, todo o resto é decorrente do entendimento da definição de arquivo.

Todavia, é perceptível constatar, na literatura arquivística, certa problemática em relação à definição do termo arquivo, advinda das dificuldades relativas às traduções e terminologias utilizadas nos diversos países. Sobre esta questão, Martín-Pozuelo Campillos (1996), destaca que o cenário e as circunstâncias sócio-políticas de cada país interferiram ou interferem na evolução deste conceito. A mesma autora explica que nos diferentes países europeus, por exemplo, isso é visível. Sobre esta questão relacionada às controvérsias e problemas de tradução do termo arquivo, Lodolini (1993, p. 61, tradução nossa) ressalta que:

(Les) 'archives', (the) 'archives', 'archiv', 'archivo', 'archivio', 'archief', parecem indicar o mesmo conceito, respectivamente em francês, em inglês, em alemão, em espanhol, em italiano, em holandês, ou seja, nas seis línguas que está elaborado o Elservier's lexion of Archive terminology. Dissemos "parecem" porque com um exame apenas um pouco a fundo nos damos conta de que, além do significado estritamente lexicológico, o valor que cada língua atribui ao termo 'archivo' é profundamente diverso.

\footnotetext{
${ }^{3}$ Publicação de S. Muller, J. A. Feith e R. Fruin, de 1898, identificada, pela maioria dos autores da Arquivologia, como o marco fundador da área.
} 
Em seu artigo Archivistics Research Saving the Profession, Ketelaar (2000) destaca que o Dictionary of Archival Terminology ${ }^{4}$, do Conselho Internacional de Arquivos (ICA), ao definir o conceito de arquivo, faz referência apenas aos registros não-correntes preservados em função de seus valores arquivísticos. O referido autor também destaca que, em muitos países europeus (Holanda, Itália, Espanha e França), por exemplo, os termos arquivos e documentos de arquivos englobam os registros correntes, semicorrentes e não correntes, ou seja, não existe uma distinção entre "records" (registros correntes e semicorrentes) e "archives" (registros não-correntes).

A respeito da evolução do conceito de arquivo, Martín-Pozuelo Campillos (1996) aponta uma concepção tripartida: uma primeira concepção, cuja importância é concedida ao lugar onde são conservados os documentos (concepção patrimonial ou patrimonialadministrativa); uma segunda concepção, na qual incorporou-se como um novo elemento a ordem, e a importância é concedida a uma boa organização, em função da utilidade e acessibilidade (concepção histórica); e uma terceira concepção, que representa a junção das duas concepções anteriores e que, na realidade, é a que tem chegado aos nossos dias e que tem como elemento configurador o conceito de proveniência.

Por sua vez, Fuster Ruiz (1999, p. 109) explica que a palavra arquivo, geralmente, possui três concepções: "como conteúdo documental" (um conjunto de documentos), "como instituição" (uma instituição onde se reúne, organiza, guarda e difunde os documentos) e "como continente ou lugar de conservação" (um local ou depósito onde se conserva e se consulta os documentos arquivísticos). Contudo, para o autor em questão (FUSTER RUIZ, 1999, p. 110, grifo do autor), antes de chegar-se a uma definição de arquivo, é necessário analisar os elementos que configuram seu conceito, a saber:

\footnotetext{
- Institucionais: o arquivo como instituição administrativa, jurídica e científica, e as entidades produtoras dos documentos que, finalmente, remetem estes aos arquivos; - Documentais: os conjuntos orgânicos de documentos, recebidos em um arquivo, procedentes de uma ou várias entidades produtoras; - Estruturais: os depósitos arquivísticos, as instalações; - Pessoais: os profissionais e seus colaboradores técnicos, especialistas em conservação e difusão documental; e Científicos e técnicos: a gestão, arquivamento e serviço documental, os trabalhos de recolhimento, organização, conservação e utilização dos fundos.
}

De acordo com este autor (1999, p. 110-111, grifo do autor), todos estes elementos devem estar representados e refletidos fielmente na definição de arquivo, uma vez que, para que um arquivo seja considerado como tal, ele necessita de:

\footnotetext{
${ }^{4}$ WALNE, Peter (Ed.). Dictionary of Archival Terminology. Munich; New York; Paris: K.G. Saur, 1984. p. 26.
} 
[...] um conteúdo (o conjunto orgânico de documentos produzidos por uma instituição), um continente (os depósitos documentais), pessoal (profissionais capacitados científica e tecnicamente para os distintos trabalhos arquivísticos), uma gestão arquivística (recolhimento, organização, conservação) e um serviço documental (utilização). É necessário, portanto, ter: o que conservar e utilizar (os documentos, os fundos documentais produzidos pelas pessoas físicas e as instituições públicas ou privadas); onde conservar e utilizar (os edifícios e instalações onde se guardam e recebem tratamento técnico estes fundos e onde podem ser colocados à disposição dos usuários); quem deve conservar, dar tratamento técnico e facilitar a utilização (os arquivistas, aqueles profissionais que possuem as bases técnicas e científicas da Arquivologia e suas ciências auxiliares, além de uma preparação jurídico-administrativa e uma certa sensibilidade para a História e a ciência em geral); e finalmente, como conservar e utilizar (tendo sempre em conta os princípios gerais que configuram a Arquivologia como ciência).

Ao abordar os princípios básicos da Arquivologia, Vivas Moreno (2004, p. 60-61, grifo do autor), por sua vez, apresenta uma periodização evolutiva do conceito de arquivo e afirma que a natureza e definição do conceito em questão, passa pelas mesmas fases da história da Arquivologia. Em um primeiro momento, de acordo com este autor, têm-se definições que "concebem o arquivo como um instrumento indutivo e funcional", nas quais o arquivo definese, fundamentalmente, como um lugar de conservação. Prosseguindo, têm-se aquelas definições "derivadas do conceito patrimonial-administrativo e jurídico do arquivo", nas quais o arquivo representa um elemento fundamental da máquina administrativa, ao adquirir uma função predominantemente jurídico-administrativa. Mais tarde, no período das revoluções burguesas no século XVIII, encontra-se o conceito de arquivo atrelado às funções culturais e históricas, no qual o arquivo é considerado um instrumento, que é utilizado com objetivos políticos. Por fim, tem-se uma ampliação do conceito de arquivo com o desenvolvimento da Arquivologia Integrada, na qual o arquivo não é conceituado como um instrumento jurídicoadministrativo unicamente e nem uma ferramenta histórica, mas integra ambas as vertentes.

Prosseguindo com sua abordagem, Vivas Moreno (2004, p. 61) apresenta três correntes ou concepções de arquivo, a saber: (1) Concepção anglo-saxônica (focada no valor primário dos documentos); (2) Concepção tradicionalista ou historicista (focada no valor secundário dos documentos); e (3) Concepção Integradora (considera de forma integradora o valor primário e o valor secundário dos documentos).

Dando seguimento nas suas reflexões, ao apresentar o seu conceito de arquivo ${ }^{5}$, Vivas Moreno (2004, p. 61-62) destaca alguns elementos que considera importantes na composição

\footnotetext{
${ }^{5}$ Definição de arquivo de Moreno (2004, p. 61): “o sistema de informação constituído por um ou mais conjuntos orgânicos de documentos, independentemente da data, forma ou suporte material, produzidos, recebidos ou
} 
da definição: (1) Do que é composto um arquivo? (2) Que documentos compõem um arquivo? (3) Quem cria gera ou produz um arquivo? (4) Como se forma um arquivo? (5) Como se tratam os documentos de um arquivo? (6) Para que se produzem os documentos? (7) Onde devem ser conservados os documentos? (8) Quem deve conservar e dar tratamento técnico?

Como se percebe, traçando-se uma análise reflexiva do que foi abordado pelos autores, até aqui citados, é possível visualizar diversas dimensões conjunturais e contextuais na evolução do conceito de arquivo, que, na verdade, representa um quebra-cabeça, no qual todas as peças se unem, formando um todo cada vez mais complexo (na medida em que as peças vão se encaixando e novas dimensões se apresentam).

\section{ESTRATÉGIAS E CRITÉRIOS DOS PROCEDIMENTOS PARA COLETA E ANÁLISE DOS DADOS}

Com o intuito de evidenciar a essência da gênese e do desenvolvimento do conceito de arquivo, na literatura brasileira, optou-se por analisar a produção de conhecimento em periódicos científicos especializados na área de Arquivologia. Cabe aqui ressaltar, que tal análise não teve a pretensão de apresentar um universo amplo em qualidades extrínsecas (formas, padrões bibliográficos e sistemas de avaliação) e intrínsecas (análise de conteúdo, produtividade e padrões de autoria). É importante, também, explicar que a escolha por um periódico especializado, deve-se ao fato de que os mesmos, além de compreenderem um canal de comunicação científica (de transmissão de informação científica), representam uma constante busca e aquisição de novos conhecimentos, bem como um debate público e coletivo de questões cientificamente relevantes e pertinentes. Neste caso, sendo os periódicos resultantes de empreendimentos editoriais referentes à Arquivologia, tem-se indicações acerca da epistemologia e da pragmática arquivística brasileira, ou seja, da construção de uma identidade científica do campo arquivístico no cenário nacional.

Diante da proposta, foram selecionados dois periódicos editados por Associações de profissionais da área, a saber: Arquivo \& Administração (publicação editada pela Associação dos Arquivistas Brasileiros desde 1972) ${ }^{6}$ e Cenário Arquivístico (publicação editada pela Associação Brasiliense de Arquivologia, entre 2002 e 2004) ${ }^{7}$. Optou-se por periódicos editados

acumulados naturalmente por qualquer pessoa - física ou jurídica, pública ou privada - no exercício de suas funções, atividades ou procedimentos, reunidos, organizados e conservados mediante princípios e metodologia científica, como garantia de direitos e como fontes de informação, em um depósito gerenciado por profissional qualificado, para obter uma gestão de qualidade".

\footnotetext{
${ }^{6}$ Foram analisados os periódicos publicados entre 1998 e 2010 - todos os volumes publicados até a finalização da pesquisa.

${ }^{7}$ Foram analisados os periódicos publicados entre 2002 e 2004 - todos os volumes publicados até a finalização da pesquisa.
} 
por Associações profissionais, por se tratarem de estruturas formais que representam um dos componentes sociais do campo científico, além de instituições consideradas importantes na circulação, preservação e registro do conhecimento.

Em relação aos procedimentos de coleta e análise dos dados, foram seguidos os seguintes passos: seleção dos artigos cujos autores são brasileiros; leitura completa (linha a linha) dos artigos selecionados, buscando identificar o termo arquivo; identificado o termo arquivo, foi feita a verificação se o contexto no qual o termo se encontra trata-se de uma conceituação ou uma caracterização de arquivo; análise dos conceitos ou caracterizações, buscando visualizar como estes foram e são abordados, traçando, também, uma relação com as considerações a respeito da concepção do termo arquivo, apresentadas por Martín-Pozuelo Campillos (1996), Fuster Ruiz (1999) e Vivas Moreno (2004). (Quadro 2).

Quadro 2-Concepções do termo arquivo

\begin{tabular}{|c|c|c|}
\hline Autor & Concepções do termo arquivo & Explicação / Observação \\
\hline \multirow{3}{*}{$\begin{array}{c}\text { Campillos } \\
\text { (1996) }\end{array}$} & $\begin{array}{l}1 \text { - Patrimonial ou patrimonial } \\
\text { administrativa }\end{array}$ & $\begin{array}{l}\text { Importância é concedida ao lugar onde são conservados os } \\
\text { documentos. }\end{array}$ \\
\hline & 2 - Histórica & $\begin{array}{l}\text { Incorporou como um novo elemento a ordem e a importância é } \\
\text { concedida a uma boa organização em função da utilidade e } \\
\text { acessibilidade. }\end{array}$ \\
\hline & $\begin{array}{l}3 \text { - Com o conceito de proveniência } \\
\text { como elemento configurador do } \\
\text { conceito }\end{array}$ & $\begin{array}{l}\text { Representa a junção das duas concepções anteriores e é a que } \\
\text { tem chegado aos nossos dias. }\end{array}$ \\
\hline \multirow{3}{*}{ Ruiz (1999) } & 1 - Como conteúdo documental & Um conjunto de documentos. \\
\hline & 2 - Como instituição & $\begin{array}{l}\text { Uma instituição onde se reúnem, organizam, guardam e } \\
\text { difundem os documentos. }\end{array}$ \\
\hline & $\begin{array}{l}3 \text { - Como continente ou lugar de } \\
\text { conservação }\end{array}$ & $\begin{array}{l}\text { Um local ou depósito onde se conservam e se consultam os } \\
\text { documentos arquivísticos. }\end{array}$ \\
\hline \multirow{3}{*}{$\begin{array}{c}\text { Moreno } \\
(2004)\end{array}$} & 1 - Anglo-saxônica & Focada no valor primário dos documentos. \\
\hline & 2 - Tradicionalista ou historicista & Focada no valor secundário dos documentos. \\
\hline & 3 - Integradora & $\begin{array}{l}\text { Considera de forma integradora o valor primário e o valor } \\
\text { secundário dos documentos. }\end{array}$ \\
\hline
\end{tabular}

Fonte: Os autores.

\section{OS CONCEITOS DE ARQUIVO NOS PERIÓDICOS BRASILEIROS}

Durante a coleta de dados, foram analisados 20 volumes dos periódicos selecionados, compreendendo 15 publicados pela Associação dos Arquivistas Brasileiros (AAB), periódico Arquivo \& Administração, e cinco publicados pela Associação Brasiliense de Arquivologia (ABARQ), periódico Cenário Arquivístico. Trabalhou-se com uma população de 92 artigos: 65 artigos (70,65\%) do periódico Arquivo \& Administração e 27 artigos (29,35\%) do periódico Cenário Arquivístico. Entre os 92 artigos publicados, 70 (76,08\%) são de autores brasileiros, sendo que, em apenas um volume, todos autores são de outras nacionalidades. Entre os 
artigos selecionados, 68 no total, $23(32,39 \%$ da amostra) apresentaram conceitos/caracterizações para o termo arquivo (Quadro 3).

Quadro 3 - Periódicos e volumes selecionados

\begin{tabular}{|c|c|c|c|c|}
\hline Periódico & Referências & $\begin{array}{c}\text { No total de } \\
\text { artigos } \\
\text { publicados }\end{array}$ & $\begin{array}{l}\text { № de artigos } \\
\text { cujos autores } \\
\text { são brasileiros }\end{array}$ & $\begin{array}{c}\text { № de artigos cujos autores } \\
\text { são brasileiros e que } \\
\text { possuem definições de } \\
\text { arquivo }\end{array}$ \\
\hline $\begin{array}{l}\text { Arquivo \& } \\
\text { Administração }\end{array}$ & $\begin{array}{l}\text { Arq. \& Adm., Rio de } \\
\text { Janeiro, v. 1, n. 1, } \\
\text { jan./jun. 1998. }\end{array}$ & 6 & 5 & 4 \\
\hline $\begin{array}{l}\text { Arquivo \& } \\
\text { Administração }\end{array}$ & $\begin{array}{l}\text { Arq. \& Adm., Rio de } \\
\text { Janeiro, v. 1, n. } 2 \text {, } \\
\text { jul./dez. 1998. }\end{array}$ & 6 & 5 & 2 \\
\hline $\begin{array}{l}\text { Arquivo \& } \\
\text { Administração }\end{array}$ & $\begin{array}{l}\text { Arq. \& Adm., Rio de } \\
\text { Janeiro, v. } 2, \text { n. } 1 / 2, \\
\text { jan./dez. } 1999 .\end{array}$ & 2 & 2 & 0 \\
\hline $\begin{array}{l}\text { Cenário } \\
\text { Arquivístico }\end{array}$ & $\begin{array}{l}\text { Cen. Arq., Brasília, v. } \\
\text { 1, n. 1, jan./jun. } 2002 .\end{array}$ & 9 & 9 & 3 \\
\hline $\begin{array}{l}\text { Cenário } \\
\text { Arquivístico }\end{array}$ & $\begin{array}{l}\text { Cen. Arq., Brasília, v. } \\
\text { 1, n. 2, jul./dez. } 2002 .\end{array}$ & 4 & 3 & 0 \\
\hline $\begin{array}{l}\text { Cenário } \\
\text { Arquivístico }\end{array}$ & $\begin{array}{l}\text { Cen. Arq., Brasília, v. } \\
\text { 2, n. 1, jan./jun. } 2003 .\end{array}$ & 4 & 3 & 0 \\
\hline $\begin{array}{l}\text { Cenário } \\
\text { Arquivístico }\end{array}$ & $\begin{array}{l}\text { Cen. Arq., Brasília, v. } \\
\text { 2, n. 2, jul./dez. } 2003 .\end{array}$ & 6 & 6 & 1 \\
\hline $\begin{array}{l}\text { Cenário } \\
\text { Arquivístico }\end{array}$ & $\begin{array}{l}\text { Cen. Arq., Brasília, v. } \\
\text { 3, n. 1, jan./jun. } 2004 .\end{array}$ & 4 & 4 & 2 \\
\hline $\begin{array}{l}\text { Arquivo \& } \\
\text { Administração }\end{array}$ & $\begin{array}{l}\text { Arq. \& Adm., Rio de } \\
\text { Janeiro, v. 3, n. 1/2, } \\
\text { jan./dez. 2004. }\end{array}$ & 6 & 5 & 1 \\
\hline $\begin{array}{l}\text { Arquivo \& } \\
\text { Administração }\end{array}$ & $\begin{array}{l}\text { Arq. \& Adm., Rio de } \\
\text { Janeiro, v. } 4, \text { n. 1, } \\
\text { jan./jun. 2005. }\end{array}$ & 5 & 1 & 1 \\
\hline $\begin{array}{l}\text { Arquivo \& } \\
\text { Administração }\end{array}$ & $\begin{array}{l}\text { Arq. \& Adm., Rio de } \\
\text { Janeiro, v. } 4, \text { n. } 2 \text {, } \\
\text { jul./dez. } 2005 .\end{array}$ & 4 & 2 & 2 \\
\hline $\begin{array}{l}\text { Arquivo \& } \\
\text { Administração }\end{array}$ & $\begin{array}{l}\text { Arq. \& Adm., Rio de } \\
\text { Janeiro, v. } 5, \text { n. } 1 \text {, } \\
\text { jan./jun. 2006. }\end{array}$ & 4 & 3 & 1 \\
\hline $\begin{array}{l}\text { Arquivo \& } \\
\text { Administração }\end{array}$ & $\begin{array}{l}\text { Arq. \& Adm., Rio de } \\
\text { Janeiro, v. 5, n. } 2 \text {, } \\
\text { jul./dez. } 2006 .\end{array}$ & 4 & 4 & 0 \\
\hline $\begin{array}{l}\text { Arquivo \& } \\
\text { Administração }\end{array}$ & $\begin{array}{l}\text { Arq. \& Adm., Rio de } \\
\text { Janeiro, v. 6, n. 1, } \\
\text { jan./jun. 2007. }\end{array}$ & 3 & 3 & 0 \\
\hline $\begin{array}{l}\text { Arquivo \& } \\
\text { Administração }\end{array}$ & $\begin{array}{l}\text { Arq. \& Adm., Rio de } \\
\text { Janeiro, v. 6, n. } 2 \text {, } \\
\text { jul./dez. } 2007 .\end{array}$ & 4 & 0 & 0 \\
\hline $\begin{array}{l}\text { Arquivo \& } \\
\text { Administração }\end{array}$ & $\begin{array}{l}\text { Arq. \& Adm., Rio de } \\
\text { Janeiro, v. } 7, \text { n. } 1, \\
\text { jan./jun. 2008. }\end{array}$ & 5 & 5 & 3 \\
\hline $\begin{array}{l}\text { Arquivo \& } \\
\text { Administração }\end{array}$ & $\begin{array}{l}\text { Arq. \& Adm., Rio de } \\
\text { Janeiro, v. } 7, \text { n. } 2 \text {, } \\
\text { jul./dez. } 2008 .\end{array}$ & 4 & 1 & 1 \\
\hline $\begin{array}{l}\text { Arquivo \& } \\
\text { Administração }\end{array}$ & $\begin{array}{l}\text { Arq. \& Adm., Rio de } \\
\text { Janeiro, v. } 8, \text { n. 1, } \\
\text { jan./dez. } 2009 .\end{array}$ & 4 & 4 & 2 \\
\hline $\begin{array}{l}\text { Arquivo \& } \\
\text { Administração }\end{array}$ & $\begin{array}{l}\text { Arq. \& Adm., Rio de } \\
\text { Janeiro, v. 9, n. 1, } \\
\text { jan./dez. } 2010 .\end{array}$ & 4 & 4 & 0 \\
\hline $\begin{array}{l}\text { Arquivo \& } \\
\text { Administração }\end{array}$ & $\begin{array}{l}\text { Arq. \& Adm., Rio de } \\
\text { Janeiro, v. } 9, \text { n. } 2 \text {, } \\
\text { jul./dez. } 2010 .\end{array}$ & 4 & 1 & 0 \\
\hline
\end{tabular}




\begin{tabular}{l|l|l|l|l}
\hline Total & 20 revistas & 92 & 70 & 23 \\
\hline
\end{tabular}

Fonte: Os autores.

Os conceitos/caracterizações encontrados foram utilizados em artigos que perpassam as mais variadas temáticas da Arquivologia, a saber:

Quadro 4 - Temáticas dos artigos com conceitos/caracterizações de arquivo

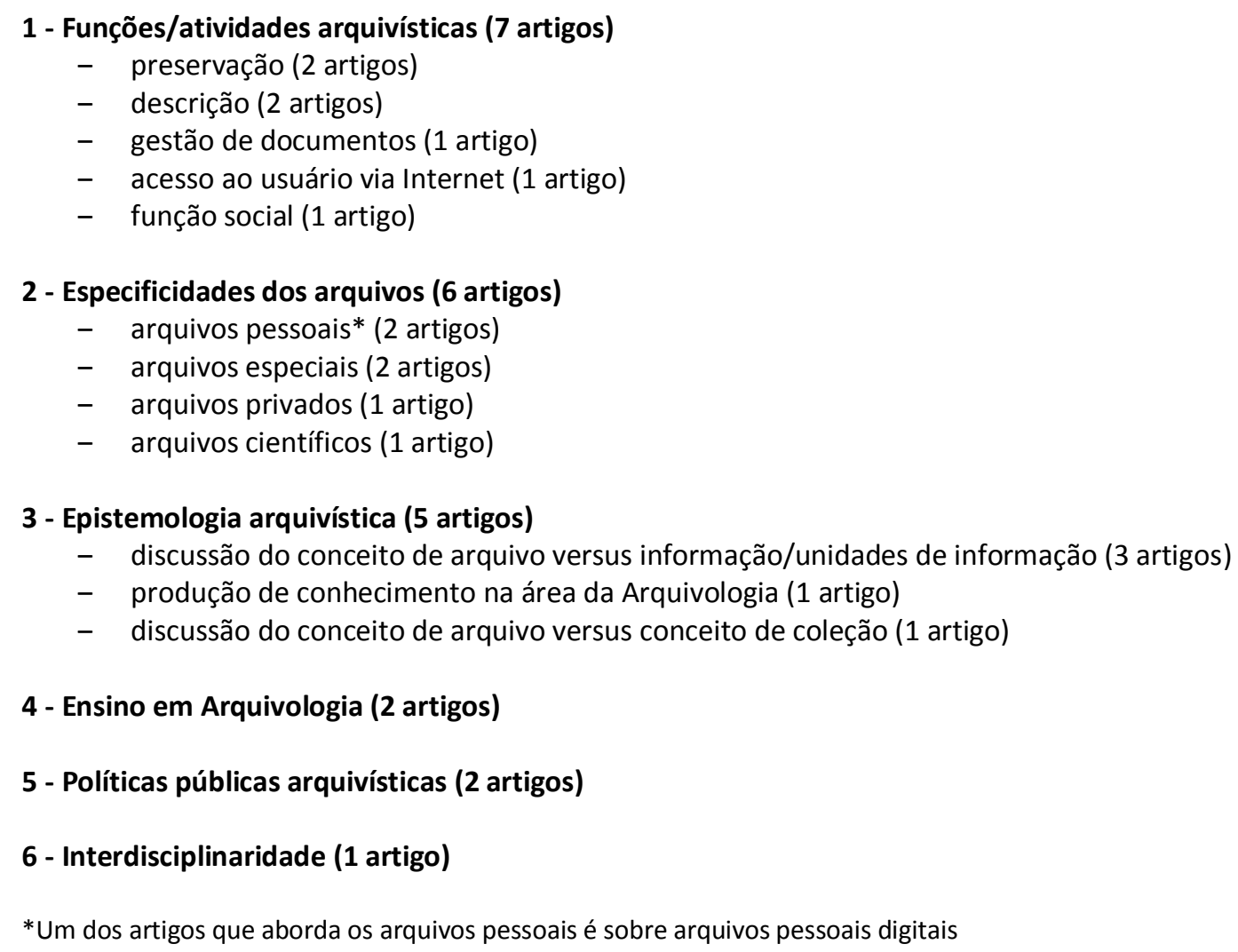

\section{4 - Ensino em Arquivologia (2 artigos)}

5 - Políticas públicas arquivísticas (2 artigos)

\section{6 - Interdisciplinaridade (1 artigo)}

*Um dos artigos que aborda os arquivos pessoais é sobre arquivos pessoais digitais

Fonte: Os autores.

Uma questão que merece destaque é o fato de artigos com temáticas que abordam a gestão eletrônica de documentos, os sistemas de gerenciamento eletrônico de documentos e documentos eletrônicos e digitais não aparecer de forma relevante nos dados supraapresentados. Este fenômeno nacional representa um paradoxo, uma vez que as dimensões, questões e impactos trazidos pelas TICs, incitam novas discussões e reflexões em torno da conceituação e caracterização de "arquivo".

Por outro lado, os dados também revelam pontos positivos, quando os artigos tratam de questões importantes para o desenvolvimento científico da área, ou seja, questões relativas à epistemologia arquivística, à interdisciplinaridade e ao ensino em Arquivologia. Ao tratarem 
estas questões, nestes artigos, a conceituação e a caracterização do conceito de "arquivo" coerentemente se fazem presentes. O mesmo acontece quando a questão central são as especificidades dos arquivos.

A respeito das facetas dos conceitos/caracterizações de "arquivo", elas se apresentam de formas diversificadas, ora se complementando ${ }^{8}$, ora se suplementando ${ }^{9}$. Trinta e cinco conceitos/caracterizações (51,47\%) citam as características dos documentos arquivísticos como a naturalidade, a integridade, a organicidade, sendo que esta última aparece em 21 conceitos/caracterizações $(30,88 \%)$. Onze conceitos/caracterizações $(16,18 \%)$ ressaltam que a formação de um arquivo independe do suporte em que os documentos são registrados. Onze conceitos/caracterizações $(16,18 \%)$ citam os arquivos enquanto patrimônio cultural ou fonte de memória e seis $(8,82 \%)$ citam os arquivos como fonte de pesquisa. Oito $(11,76 \%)$ conceitos/caracterizações citam os arquivos como elementos de prova/testemunho e informação. Dez conceitos/caracterizações $(14,70 \%)$ relacionam arquivo com os termos informação, campo informacional ou suporte de informação. Enfim, apenas três $(4,41 \% \%)$ conceitos/caracterizações citam os arquivos enquanto recursos estratégicos, agências estratégicas ou apoio administrativo. Cabe aqui ressaltar, que esta última faceta proporciona o seguinte questionamento: se, para alguns teóricos, os arquivos são conjuntos de documentos que nascem em razão de questões administrativas, não seria coerente que a ocorrência de conceitos/caracterizações que apontam os arquivos, enquanto recursos de apoio administrativo, fosse mais representativa?

Entre os 68 conceitos/caracterizações encontrados, 22 (32,35\%) têm, na sua estrutura, citações de autores, instituições ou manuais e dicionários estrangeiros (Quadro 5); 16 (23,53\%) integram ou compreendem citações de autores, instituições ou manuais e dicionários brasileiros; entretanto, 30 (44,12\%) conceitos/caracterizações são construções próprias dos autores $^{10}$. Como se percebe no Quadro 5, os conceitos/caracterizações sofrem influências de autores/pesquisadores de diversos cenários internacionais, como, por exemplo: Schellemberg dos EUA; Jenkinson, da Grã-Bretanha; Cook, Eastwood, Rosseau e Couture, do Canadá; Heredia Herrera, da Espanha; Duchein, da França; Lodolini, da Itália; Muller, Feith e Fruin, Thomassem e Ketellar, da Holanda; Silva, de Portugal; etc.

\footnotetext{
${ }^{8}$ Se juntam tornando o conceito de arquivo íntegro e completo.

${ }^{9}$ Se juntam ao conceito de arquivo para ampliá-lo, esclarecê-lo ou aperfeiçoá-lo.

${ }^{10}$ Baseadas nas ideias presentes e consolidadas no conhecimento arquivístico.
} 
Quadro 5 - Citações de autores, instituições ou manuais e dicionários

\begin{tabular}{|c|c|c|}
\hline Número de citações & $\begin{array}{c}\text { Autores, instituições ou manuais e } \\
\text { dicionários estrangeiros }\end{array}$ & $\begin{array}{c}\text { Autores, instituições ou manuais e } \\
\text { dicionários brasileiros }\end{array}$ \\
\hline Quatro citações & $\begin{array}{l}\text { Schellemberg; Manual dos Arquivistas } \\
\text { Holandeses (Muller, Feith e Fruin) }\end{array}$ & - \\
\hline Três citações & - & Paes \\
\hline Duas citações & Jenkinson; Cook; Thomassem & $\begin{array}{l}\text { Fonseca; Camargo e Bellotto; Lei Federal } \\
8.159 / 91\end{array}$ \\
\hline Uma citação & $\begin{array}{l}\text { Schwartz e Cook; Eastwood; Rosseau e } \\
\text { Couture; Malheiro; Londolini; Heredia; } \\
\text { Giddens; Ketelaar; Duchein; Dicionário } \\
\text { Internacional de Terminologia } \\
\text { Arquivísitica; Bureau Canadien des } \\
\text { Archivistes; Mykland; Manual de } \\
\text { Arquivologia Publicado pela Direção } \\
\text { de Arquivos da França e pela } \\
\text { Associação dos Arquivistas Franceses; }\end{array}$ & $\begin{array}{l}\text { Montiel; Bellotto; Associação dos } \\
\text { Arquivistas Brasileiros }\end{array}$ \\
\hline
\end{tabular}

Fonte: Os autores.

Em relação às concepções do termo arquivo no cenário internacional, apresentadas por Martín-Pozuelo Campillos (1996), Fuster Ruiz (1999) e Vivas Moreno (2004), os conceitos/caracterizações encontrados estão consolidados em torno de duas temáticas centrais, as quais, na maioria das vezes, aparecem simultaneamente: arquivo, enquanto conteúdo documental, ou seja, um conjunto de documentos (49 conceitos - 72,06\%), e arquivo, tendo o conceito de proveniência como elemento configurador (40 conceitos 58,82\%) (Quadro 6). Este fenômeno, de certa forma, retrata e explica a ocorrência de conceitos/caracterizações que se reportam às características dos documentos arquivísticos. Ora, se os arquivos são um conjunto de documentos, é importante delimitar tais documentos. Vale, também, destacar que o elo caracterizador de um conjunto documental íntegro, de acordo com a teoria arquivística, é o contexto de proveniência.

Quadro 6 - Panorama conceitual de acordo com as abordagens de Campillos (1996), Ruiz (1999) e Moreno (2004)

\begin{tabular}{l|l|l|l}
\hline \multirow{2}{*}{ Autor } & \multicolumn{1}{|c|}{$\begin{array}{c}\text { Concepções do } \\
\text { conceito arquivo }\end{array}$} & Explicação / Observação & $\begin{array}{c}\text { Quantidade } \\
\text { de conceitos } \\
\text { relacionados }\end{array}$ \\
\hline \multirow{3}{*}{$\begin{array}{l}\text { Campillos } \\
(1996)\end{array}$} & $\begin{array}{l}\text { 1- Patrimonial ou } \\
\text { patrimonial } \\
\text { administrativa }\end{array}$ & $\begin{array}{l}\text { Importância é concedida ao lugar onde são conservados } \\
\text { os documentos. }\end{array}$ & $8(11,76 \%)$ \\
\cline { 2 - 4 } & 2 - Histórica & $\begin{array}{l}\text { Incorporou como um novo elemento a ordem e a } \\
\text { importância é concedida a uma boa organização em } \\
\text { função da utilidade e acessibilidade. }\end{array}$ & $6(8,82 \%)$ \\
\cline { 2 - 4 } & $\begin{array}{l}\text { 3- Com o conceito de } \\
\text { proveniência como } \\
\text { elemento configurador }\end{array}$ & $\begin{array}{l}\text { Representa a junção das duas concepções anteriores e é a } \\
\text { que tem chegado aos nossos dias. }\end{array}$ & $40(58,82)$ \\
\hline
\end{tabular}


ARTIGOS

\begin{tabular}{|c|c|c|c|}
\hline Autor & $\begin{array}{l}\text { Concepções do } \\
\text { conceito arquivo }\end{array}$ & Explicação / Observação & $\begin{array}{l}\text { Quantidade } \\
\text { de conceitos } \\
\text { relacionados }\end{array}$ \\
\hline & do conceito & & \\
\hline \multirow{3}{*}{ Ruiz (1999) } & $\begin{array}{l}1 \text { - Como conteúdo } \\
\text { documental }\end{array}$ & Um conjunto de documentos. & $49(72,06 \%)$ \\
\hline & 2 - Como instituição & $\begin{array}{l}\text { Uma instituição onde se reúne, organiza, guarda e difunde } \\
\text { os documentos. }\end{array}$ & $7(10,29 \%)$ \\
\hline & $\begin{array}{l}3 \text { - Como continente ou } \\
\text { lugar de conservação }\end{array}$ & $\begin{array}{l}\text { Um local ou depósito onde se conserva e se consulta os } \\
\text { documentos arquivísticos. }\end{array}$ & $8(11,76 \%)$ \\
\hline \multirow{3}{*}{$\begin{array}{l}\text { Moreno } \\
(2004)\end{array}$} & 1 - Anglo-saxônica & Focada no valor primário dos documentos. & $1(1,47 \%)$ \\
\hline & $\begin{array}{l}2 \text { - Tradicionalista ou } \\
\text { historicista }\end{array}$ & Focada no valor secundário dos documentos. & $7(10,29 \%)$ \\
\hline & 3 - Integradora & $\begin{array}{l}\text { Considera de forma integradora o valor primário e o valor } \\
\text { secundário dos documentos. }\end{array}$ & $6(8,82 \%)$ \\
\hline Não se aplica & - & - & $2(2,94 \%)$ \\
\hline
\end{tabular}

Fonte: Os autores.

As outras sete concepções apresentadas por Martín-Pozuelo Campillos (1996), Fuster Ruiz (1999) e Vivas Moreno (2004), somadas às concepções que não se aplicam, juntas, estão representadas em 45 conceitos/caracterizações (66,17\%) (Quadro 6). Além disso, foi possível perceber que estes também, na maioria das vezes, encaixam-se simultaneamente em duas ou mais concepções, incluindo ou não as duas temáticas centrais citadas anteriormente. Acreditase que tal fato, associado à influência de autores de diversas localidades e às diversas circunstâncias em que o termo arquivo é conceituado e caracterizado, conforme anteriormente apresentado, pode representar a busca de uma nova orientação e extensão dos domínios, integrando as diversas concepções, de modo que estas se complementem e/ou se suplementem, tendo em vista a complexidade e as diversas dimensões e conjunturas que se apresentam à Arquivologia, aos arquivos e aos documentos arquivísticos. Isso reforça o pensamento de Cook (1997), quando o mesmo afirma que a Arquivologia não possui uma escola exclusiva de pensadores, mas, sim, de uma colagem rica de camadas de ideias que existem simultaneamente ou se misturam, que exibem diferenças de ênfase e que representam, em algumas circunstâncias, "o pêndulo de balanços do pensamento para frente e para trás".

\section{CONSIDERAÇÕES FINAIS}

Ao traçarmos uma análise do que foi abordado pelos autores brasileiros, nos periódicos selecionados, é possível visualizar diversas dimensões e facetas do conceito de arquivo, suas caracterizações e suas tendências no cenário nacional. Em relação às tendências e caracterizações, ora são de cunho próprio, ora são influenciadas por autores e/ou 
publicações internacionais, tanto advindas do velho mundo como do novo mundo. Além disso, tal conceituação/caracterização perpassa por diversos domínios epistemológicos e pragmáticos da Arquivologia, mas, de acordo com a maioria, os arquivos compreendem um conjunto de documentos com características próprias, que têm o conceito de proveniência como elemento configurador, independente do formato e do suporte em que estão registrados, e que podem ser valiosos enquanto patrimônio cultural, fonte de memória, fonte de pesquisa e como elementos de prova/testemunho e informação.

Destarte, como pode ser observado, falar de arquivo não é tão simples; o termo compreende e integra diversos sentidos, tanto no senso comum quanto no âmbito científico. Além disso, a conceituação/caracterização do termo envolve múltiplas facetas que se movimentam e se articulam, tendo em vista as diversas dimensões conjunturais e contextuais, bem como as diferenças de ênfase que se pretende anunciar. Este fenômeno permite fazer uma analogia a "uma colagem rica de camadas de ideias", que existem simultaneamente ou se misturam (Cook , 1997), perpassando por várias temáticas e domínios do saber arquivístico, e que, por sua vez, encaixam-se como peças de um quebra-cabeça.

Finalizando, acredita-se que os conceitos/caracterizações de arquivo não precisam representar linhas retas e paralelas, mas podem compreender um complexo que perpassa todas as concepções e ângulos, semelhante a uma teia. Diante desta constatação, para evitar ambiguidades e contradições, considera-se, assim como Vivas Ruiz (1999, p. 110-111), que todos os elementos que circundam o termo devem estar representados e refletidos fielmente na sua definição, como, por exemplo: conteúdo, continente, pessoal, gestão e serviços arquivísticos, ou seja, o que, onde, quem e como.

\section{Referências}

CAMPILLOS, Maria da Paz Matin-Pozuelo. La construcción teórica em arqchivística: el princípio de procedencia. Madri: Universidad Carlos III de Madri, 1996.

COOK, T. What is past is prologue: a history of archival ideas since 1898 , and the future paradigm shift. Archivaria, n. 43, Spring 1997. Disponível em:

<http://www.mybestdocs.com/cookt-pastprologue-ar43fnl.htm>. Acesso em: 22 abr. 2012.

FONSECA, M. O. K. Arquivologia e ciência da informação: (re) definição de marcos interdisciplinares. 2004. 181f. Tese (Doutorado em Ciência da Informação) - Universidade Federal do Rio de Janeiro, Rio de Janeiro, 2004.

KETELAAR, E. Archivistics research saving the profession. The American Archivist, v. 63, p. 322340, Fall/Winter 2000.

LONDOLINI, Elio. Archivística: princípios y problemas. Madrid: ANABAD, 1993. 
MORENO, Agustin Vivas. Princípios básicos de la archivística. In: LORENZO CADARSO, Pedro Luis; MORENO, Agustin Vivas. Lecciones de archivistica general y documentacion del patrimonio historico. Badajoz: Universidad de Extremadura, 2004. p. 57-71.

ROSSEAU, J.; COUTURE, C. Fundamentos da disciplina arquivística. Lisboa: Publicações Dom Quixote, 1998.

RUIZ, Francisco Fuster. Archivistica, archivo, documento de archivo...: necessidade de clarificar los conceptos. Anales de Documentación, v. 2, p. 103-120, 1999.

SILVA, Wilson Santiago. Arquivo de IHGB. Arq. \& Adm., Rio de Janeiro, v. 4, n. 1, p.54-80, jul./dez. 2005.

THOMASSEM, T. The development of Archival Science and its European dimension. In: SEMINAR FOR ANNA CHRISTINA ULFSPARRE. Swedish National Archives, 1999, Estocolmo. Annals... Estocolmo, Feb. 1999. Disponível em: <http://www.daz.hr/arhol/thomassen.htm>. Acesso em: 22 abr. 2012.

THOMASSEM, Theo. Uma primeira introdução à Arquivologia. Arquivo \& Administração. Rio de Janeiro, v. 5, n. 1, p. 5-16, jan./jun. 2006. 